\title{
LA JUDICIALIZACIÓN DE LOS PROCESOS DE DESCENTRALIZACIÓN Y AUTONOMÍA. EL CASO DEL TRIBUNAL CONSTITUCIONAL ESPAÑOL Y EL DESARROLLO AUTONÓMICO ${ }^{1}$
}

\author{
JORGE O. BERCHOLC ${ }^{2}$
}

\section{RESUMEN}

El sustrato teórico e ideológico para dar soporte a un proceso de descentralización es variado y presenta matices contradictorios. El modelo constitucional de federalismo "integrado", con muchas competencias concurrentes, hace que ellas sean más difusas generando conflictos por la delimitación de las mismas. Por ende, tomando como ejemplo el caso español, el Tribunal Constitucional debe asumir una actividad intensa y un rol muy activo, aún mayor del que generalmente debe asumir un alto tribunal, para resolver conflictos de competencia en federaciones de modelo "dualista".

Por la dispersión de opiniones y enfoques de la doctrina resulta menester producir conocimiento objetivo, riguroso $\mathrm{y}$

1 Artículo entregado por el autor el 29 de junio de 2016 y aprobado el 20 de noviembre de 2016

2 Investigador del Instituto de Investigaciones Jurídicas y Sociales Ambrosio L. Gioja, Universidad de Buenos Aires, Profesor Catedrático de Teoría del Estado y de Postgrado y Doctorado de la Facultad de Derecho de la Universidad de Buenos Aires, Profesor Catedrático de Sociología Jurídica y de Metodología de la investigación, Universidad Abierta Interamericana. 
microscópico, que permita acercarse a lo nodal del proceso y comprenderlo con más sofisticación, no solamente desde posiciones, en exceso, "generalistas".

\section{PALABRAS CLAVE}

Descentralización, Tribunal Constitucional, desarrollo autonómico y control de constitucionalidad

\section{ABSTRACT}

The theoretical and ideological substratum to give support to a process of decentralization, is changed and presents contradictory shades. The constitutional model of "integrated" federalism, with many concurrent competences, does that they are more diffuse generating conflicts for the delimiting of the same ones. In the Spanish case the TC must assume an intense activity and a very active, major role of the one that generally must assume a high court, to solve conflicts of competence in federations of "dualistic" model.

The dispersion of opinions and approaches of the doctrine require to produce objective, rigorous and microscopic knowledge, which allows to approach at the process and to understand it with more sophistication, not only from positions, in excess, "general practitioners".

\section{KEY WORDS}

Decentralization, Constitutional Court, autonomous development and judicial review 


\section{INTRODUCCIÓN}

El trabajo presenta la articulación readaptada de un marco teórico general que enmarca los resultados relacionados de una investigación empírico-cuantitativa reciente, parte de una investigación mayor, sobre el Tribunal Constitucional español. La relación entre un marco teórico preexistente y los hallazgos relacionados y pertinentes de una investigación posterior, completa el circuito científico de generación de conocimiento con metodología de triangulación, que resulta recomendable a fin de la sustentabilidad de la producción científica, entendida como un proceso de producción de conocimiento arduo, sistemático y diacrónico.

El trabajo presenta insumos, datos y evidencia empírica, cuidadosamente desagregada, de un caso concreto de judicialización extrema de un proceso de descentralización política, que se observa en España. El caso se presenta a través del conflicto entre las comunidades autónomas españolas, entidades parte del Estado central y el propio Estado central español.

El análisis y presentación de esos insumos, y las razones epistemológicas que hacen menester el uso de evidencia empírica para la debida sustentación y corroboración de enunciados sobre estos tópicos y para superar la dispersión de opiniones altamente contradictorias de la doctrina se presentan en las varias secciones del trabajo.

Las mismas están precedidos por una primera sección que presenta distintos enfoques doctrinarios, de justificación teórica sobre las bondades de un proceso de descentralización. El enunciado de ese marco teórico general muestra, por la dispersión observable 
y por sus contradicciones, las limitaciones de los esquemas generalistas que carezcan de evidencia e insumos empíricos para su mayor consistencia y desagregación analítica.

Se incluye una sección final con conclusiones sobre el caso español, las cuales permiten la identificación expresa de consecuencias y problemas en un proceso de descentralización política sometido a la jurisdicción.

El trabajo pretende aportar, a través de la confrontación de los marcos teórico-doctrinarios existentes con los insumos y evidencias empíricas de una investigación sobre el Tribunal Constitucional español, en su producción sobre el control judicial de un proceso de descentralización política, nuevas perspectivas y conocimiento que permitan identificar con mayor desagregación y eficacia los conflictos, tensiones, implicaciones y complejidades de los procesos de descentralización que no son buenos intrínsecamente, y que deben ser observados con atención, considerando las condiciones objetivas de posibilidad y realización en cada caso concreto.

También se pretende realizar un aporte que permita desmitificar ciertas categorías conceptuales, que son tratadas sin el rigor científico necesario para el desarrollo de un conocimiento consistente, a fin de superar debates estériles, difusos y contradictorios. 


\section{COMPLEJIDADES EN LA JUSTIFICACIÓN TEÓRICA DE LA DESCENTRALIZACIÓN}

El sustrato teórico e ideológico para dar soporte a un proceso de descentralización es variado y presenta matices contradictorios.

En principio, los más utilizados son:

1. El argumento prodemocrático o democratista de la participación;

2. De la transparencia y el control de gestión de cuño más republicanista;

3. La desburocratización y la eficiencia que parecen responder a criterios sistémicos; y,

4. El principio de subsidiariedad, que puede ser leído en clave neoliberal o democratista.

\section{Justificación "democratista"}

Uno de los argumentos teóricos más utilizados para llevar adelante y justificar un proceso de descentralización es el que rescata los beneficios y aportes que, "para democratizar la democracia", se obtendrían, a través de la participación más directa y cercana de la ciudadanía en el proceso de toma de decisiones de las agencias estatales.

Hablar de "democratizar la democracia", de darle sustantividad a la democracia representativa o de generar mecanismos democráticos de participación directa o semidirecta, resulta un debate crucial de la ciencia política que no está en absoluto saldado, no sólo en los hechos de la política sino también en la vida académica y doctrinaria. 
No obstante, en general se acepta, que lo intrínsecamente bueno de un proceso descentralizador es aquello prodemocrático que se genera, a través de una mayor participación ciudadana, de una mayor cercanía y aproximación de la población con los dirigentes que directamente toman las decisiones, con el incentivo de que las demandas de la población con respecto a aquellos temas que más le preocupen lleguen más rápidamente y sin filtraciones ni deformaciones al corazón del sistema político, en pos de superar la apatía ciudadana, la "privatización" de la política y obteniendo así, por parte del sistema, respuestas congruentes que resulten espejo sociológico fiel de las demandas, como consecuencia, precisamente, de esa cercanía.

En este caso, hay una comunicación fluida y una sensibilidad mayor, porque el dirigente que convive en unidades distritales más pequeñas con los ciudadanos, comparte con ellos el espacio público cotidianamente, sin mediaciones institucionales ni de los medios de comunicación; ello resulta plausible, en tanto ese funcionario demandado tenga los recursos necesarios para poder responder a ese cúmulo de demandas que van a caer sobre su responsabilidad.

Si se produjera un eficiente funcionamiento del sistema que redunde en a) demandas ciudadanas genuinas y b) respuestas congruentes, rápidas y satisfactorias de las agencias estatales/ políticas en un nivel cuantitativo y cualitativo aceptable, se estarían resolviendo, en efecto, varios problemas vinculados a las cuotas de legitimidad política de la autoridad, menester para una ordenada y eficaz acción de gobierno.

Sin embargo, debemos advertir que esa cercanía, plausible para la obtención de óptimos niveles de legitimidad, desde las dos 
perspectivas señaladas en el párrafo anterior, puede tornarse contraproducente y aún complicar los niveles funcionales de legitimidad, si las agencias estatales no poseen los recursos necesarios -económicos, logísticos y humanos- para dar rápida, eficaz y satisfactoria respuesta a las demandas.

Esta cuestión no es novedosa, Hamilton y Madison, "padres fundadores" de los Estados Unidos de Norteamérica, en la época preconstitucional a fines del siglo XVIII, y durante el proceso de ratificación de la misma, en los "papers" de "El Federalista" hacían hincapié en esta dificultad de la democracia.

Ellos fueron muy críticos con los parlamentos estaduales, institución a la que consideraban integrada por funcionarios apasionados, poco racionales y, aún en ocasiones, usando epítetos más duros por déspotas y aventureros, entre otros. Y se referían en esos términos porque les reprochaban su admisión de cualquier tipo de demanda por parte de poblaciones muy activas, que actuaban en forma facciosa; mostrándose incapaces de entender los intereses permanentes de la comunidad.

En los debates durante los años previos a la consagración de la Constitución, y aún durante la Convención Constituyente, se buscaron mecanismos y diseños institucionales que pusieran freno a la avalancha de demandas populares transformadas en leyes positivas.

Estos diseños de control, en clave "republicanista", buscaban evitar que las presiones dadas por la cercanía entre demandantes (ciudadanos) y demandados (representantes políticos) generaran esa fiel polea de transmisión de demandas con sanción de normas positivas, un excepcional ejercicio democrático participativo, 
pero visto desde otra perspectiva, una serie de actos irracionales y apasionados de demagogos dispuestos a satisfacer cualquier demanda, sin medir las consecuencias ni observar las objetivas condiciones de posibilidad.

Si justificamos en un sustrato teórico "democratista" la viabilidad y plausibilidad de un proceso de descentralización, previamente debemos afinar la idea respecto al tipo de democracia que pretendemos y a sus condiciones objetivas de posibilidad y de desarrollo eficaz. Más allá de gustos y de preferencias en clave teórica, habrá que cuidar que la cercanía y participación no terminen complicando los sistemas políticos que, aún sin semejante nivel de expansión democrática, están sometidos a disfunciones o complejidades en el proceso de toma de decisiones, tanto de las agencias estatales como de las organizaciones representativas.

Una de las disfunciones que se enquistan, merced a las promesas incumplidas de la burocracia y la oligarquización, es el denominado clientelismo ${ }^{3}$, atribuido a las estructuras excesivamente burocratizadas y cupulares, que se valen de una suerte de grupos de mano de obra disponible para llevar a cabo acciones de choque, presión o avanzada, en pos de fines favorables para la estructura y/o cúpula y por las cuales esos grupos reciben favores o privilegios.

Se argumenta que la descentralización ayudaría a resolver las prácticas clientelares. ¿Qué nos garantiza que en un proceso

3 “Término técnico para una relación de dependencia recíproca entre dos actores (individuos o grupos) que disponen de diferentes recursos que utilizan para favorecerse mutuamente." NOHLEN, Dieter. Diccionario de Ciencia Política, Tomo 1, Editorial Porrúa, México, 2006, p. 212. 
descentralizador no vayamos a tener mayores problemas de clientelismo? Ello ante la superposición de estructuras burocráticas y donde la cercanía cotidiana entre ciudadanos y representantes puede generar conflictos sin mediación posible entre ambas partes, generando presiones y tensiones de difícil pronóstico y resolución.

De modo que tampoco lisa y llanamente, en forma mecánica y pacífica, habrá una superación de las prácticas clientelares de la mano de un proceso de descentralización.

\section{Justificación "republicanista"}

Si observamos que el origen del sistema de frenos y contrapesos tiene relación con el control del poder político, y que una de sus vertientes históricas es la experiencia en la consolidación del proceso constitucional en los Estados Unidos de Norteamérica, debemos remitir a lo ya citado de Hamilton y Madison, en "El Federalista", y su preocupación por el control de los actos normativos influenciados por las mayorías.

En clave "republicanista", se puede justificar la plausibilidad de un proceso descentralizador del poder en términos de transparencia en los actos de gobierno, de control del ejercicio del poder, de mayor limitación a partir del proceso de cesión de competencias y de fragmentación del poder central que, de otro modo, se tornaría omnímodo y autocrático.

Es útil referir aquí que, saliendo de la matriz "democratista" de la participación y profundizando en mecanismos efectivos de transparencia y fragmentación del poder, deben desagregarse distintas áreas posibles que deberán mensurarse para efectuar 
análisis comparados realísticos sobre viabilidad y plausibilidad del proceso de descentralización, aplicado a circunstancias espaciales y temporales concretas, en pos de evitar juicios prescriptivos generalistas.

En ese sentido, habrá que distinguir entre dos niveles: a) descentralización del poder -competencias derivadas a cada unidad constituyente- y b) descentralización del proceso de toma de decisiones a nivel federal -importancia del nivel decisorio de cada unidad constituyente dentro de las instituciones de la federación-.

A su vez el primer nivel debe desagregarse en dos aspectos: 1) alcance del poder ejercido por cada unidad constituyente o cantidad de competencias derivadas y 2) grado de autonomía que cada unidad tiene para desempeñar las funciones derivadas.

Esta distinción se explica, por ejemplo, con el caso de un Estado central con muchas competencias descentralizadas (aspecto 1), pero que ejerce controles muy estrictos sobre el ejercicio por parte del ente sub-estatal o local de esas mismas competencias derivadas (aspecto 2).

Puede darse el caso opuesto de pocas competencias derivadas (aspecto 1) pero con gran autonomía para su ejercicio (aspecto 2).

Las posibles variables o indicadores útiles para mensurar en un trabajo comparado el grado de descentralización de un sistema político, deberían ser desagregadas en descentralización legislativa, administrativa, financiera, para agencias no gubernamentales y marco normativo constitucional. 
Si bien estas variables requieren algún nivel de precisión mayor que el que someramente se hace en este artículo, resultan una buena aproximación a los principios epistémicos y metodológicos eficaces al fin propuesto ${ }^{4}$.

Los riesgos de los sistemas de frenos y contrapesos a efectos del control y la división del poder, que implican también a las ideas descentralizadoras para mayor control del proceso de toma de decisiones y para el establecimiento de límites al poder central, son los de su excesiva fragmentación.

Ello puede traducirse en una mayor valoración y protección de los derechos individuales y subjetivos respecto del poder central, pero en un debilitamiento de los procesos de consagración de derechos colectivos sociales. El exceso de subjetivismo o individualismo, en la justificación teórica "republicanista", puede entorpecer procesos sociales y/o estatalistas de inclusión y consagración de derechos sociales y expansión de políticas de intervención estatal, tendientes a solucionar problemas generados por desequilibrios económicos, desigual distribución de la riqueza, etc.

En general las ideas intervencionistas, o la toma de decisiones centralizada alimenta la idea de un poder central fuerte que contrapese los desequilibrios del libre mercado. En esta línea, se encuentran los variados y actuales desarrollos aggiornados del denominado "decisionismo estatal", cuya herramienta normativa más conocida y utilizada en las últimas décadas por todo gobierno de cualquier signo político han sido los célebres decretos de necesidad y urgencia (denominación en

4 WATTS, Ronald. Sistemas federales comparados, Marcial Pons, Madrid, 2006, pp. 185 y ss. 
Argentina), o medidas provisorias (en Brasil), o executive order (en los EE.UU.).

\section{Justificación "sistémica"}

En las teorías sistémicas también pueden encontrarse justificaciones importantes para sustentar un proceso de descentralización.

El proceso de desburocratización y la cercanía del individuo demandante respecto de la agencia estatal, sub-estatal o local requiere, además, un proceso de burocracia más simple que pueda dar respuestas más efectivas y rápidas.

No cabe esperar que aquellos entes que deberían renunciar al poder político o presupuestario lo hagan voluntariamente; esta es una lección básica de ciencia política, ya enunciada en la conocida "ley de hierro de las oligarquías", por el sociólogo alemán ROBERT MICHELS.

Se debe ser prudente ante el impulso de un proceso de desburocratización de los entes estatales centrales, pues la proliferación de entes descentralizados está produciendo una evidente superposición de estructuras burocráticas y, como lógica consecuencia, una abundancia normativa, producto de esas estructuras.

La justificación sistémica puede referirse también a la eficacia en la provisión de los servicios públicos, como objetivo válido para impulsar la descentralización de los organismos del área.

En el marco de criterios de racionalidad economicista, es posible que el proceso de descentralización revierta en una mayor eficacia 
de la provisión de servicios públicos, entendidos en sentido amplio: educación, salud, policía, etc.

\section{Justificación por aplicación del principio de subsidiariedad}

El principio de subsidiariedad pretende limitar la esfera de acción de los entes estatales, sosteniendo que todo aquello que puede ser bien y eficazmente hecho por los individuos o por las entidades sub-estatales o locales no tiene por qué ser invadido por ninguna entidad estatal.

El principio de subsidiariedad tiene por objeto garantizar que el proceso de toma de decisiones se desarrolle del modo más cercano posible al ciudadano.

En el caso de la Unión Europea el principio ha sido receptado por las normas jurídicas positivas aplicables a través de lo dispuesto por el artículo 3 B del Tratado de la Comunidad Europea, en pos de una mayor legitimidad y consenso por parte de los ciudadanos europeos de cada país, respecto de las instituciones comunitarias supranacionales. A fin de cumplir tal propósito, la UE se autoimpone una comprobación constante de que la acción que deba emprenderse a escala comunitaria se justifique en relación con las posibilidades que ofrece el nivel nacional, regional o local. Concretamente, es un principio según el cual la Unión no actúa, excepto para los sectores de su competencia exclusiva, hasta que su acción se muestre más eficaz que una acción emprendida a nivel nacional, regional o local.

Los fundamentos jurídicos del principio en la UE los hallamos en: 


\section{-Tratado de Maastricht (1992) artículo 3 B del Tratado de la} Comunidad Europea (TCE): "La Comunidad actuará dentro de los límites de las competencias que le atribuye el presente Tratado y de los objetivos que éste le asigna. En los ámbitos que no sean de su competencia exclusiva, la Comunidad intervendrá, conforme al principio de subsidiariedad, sólo en la medida en que los objetivos de la acción pretendida no puedan ser alcanzados de manera suficiente por los Estados miembros, y, por consiguiente, puedan lograrse mejor, debido a la dimensión o a los efectos de la acción contemplada, a nivel comunitario. Ninguna acción de la Comunidad excederá de lo necesario para alcanzar los objetivos del presente Tratado".

\section{- Título I del Tratado de la Unión Europea (TUE) en referencia} al artículo 3 B del TCE: "[...] Los objetivos de la Unión se alcanzarán conforme a las disposiciones del presente tratado, en las condiciones y según los ritmos previstos y en el respeto del principio de subsidiariedad tal y como se define en el artículo $3 \mathrm{~B}$ del Tratado Constitutivo de la Comunidad Europea".

\section{- Preámbulo del Tratado de la Unión Europea: “[...]} RESUELTOS a continuar el proceso de creación de una unión cada vez más estrecha entre los pueblos de Europa, en la que las decisiones se tomen de la forma más próxima posible a los ciudadanos, de acuerdo con el principio de subsidiariedad, [...]".

Podrían rescatarse dos acepciones posibles del principio de subsidiariedad:

1) En clave conservadora, neoliberal, que persigue la eficiencia económica de sistemas descentralizados y la no invasión de esferas individuales, poniendo el límite a poderes centrales sumamente concentrados. 
2) En los términos de la enunciación del principio por las normas jurídicas citadas de la UE, en la búsqueda de consensos y niveles de legitimidad funcionales para las instituciones supranacionales que podría enunciarse de esta manera: ¿para qué vamos a ceder competencias a entes supranacionales más alejados de las poblaciones a las cuales les tenemos que dedicar la decisión política, si lo puede hacer el ente inferior, nacional o subnacional de manera eficaz y en sintonía y cercanía con el sujeto colectivo destinatario de la decisión?

INSUMOS ÚTILES PARA LA CORROBORACIÓN DE LA EFICACIA DE UN PROCESO DE DESCENTRALIZACIÓN. LA JUDICIALIZACIÓN DEL PROCESO. EL CASO ESPAÑOL

En España y Latinoamérica el análisis del Derecho suele emprenderse tradicionalmente $\mathrm{y}$, aún hoy con frecuencia, de una manera prescriptiva y filosófica más relacionada al campo del "deber ser". Se privilegia el discurso abstracto y normativista en desmedro de la generación de datos e insumos de conocimiento básico para, a partir de allí, plantearse prospectivas, recomendaciones o intervenciones sobre las instituciones.

En países anglosajones, en particular Estados Unidos y Canadá, se producen una gran cantidad de estudios empíricos sobre Derecho, la mayoría de ellos cuantitativos. Se interesan particularmente por las relaciones interpoderes a partir de datos e insumos materiales sobre la producción de las agencias estatales, la performance de instituciones y del personal que desempeña los roles institucionales, por ejemplo tribunales y jueces, los sesgos, tendencias o comportamientos más comunes y/o repetidos de esas producciones; y luego de ser detectados esos patrones, 
se orientan a la búsqueda de las variables explicativas de esos comportamientos, a partir de allí se efectúan los análisis agregados y cualitativos, las hipótesis complejas e interrelacionadas, las prospectivas y recomendaciones operativas o de intervención estatal.

Este tipo de mirada, más desagregada y microscópica sobre el quehacer cotidiano de las agencias y los funcionarios judiciales permite ver cosas no visibles para las doctrinas demasiado generalistas o prescriptivistas, o en exceso sesgadas a lo filosófico. ${ }^{5}$

La generación de conocimiento riguroso, en términos empíricocuantitativos, nos aproxima a la realidad de los conflictos sobre los que opera el Derecho y sus agencias. Situarnos frente a la realidad nos enfrenta a otras perspectivas que nos indican que los conflictos suelen decidirse por cuestiones que no se relacionan con los tópicos filosóficos, prescriptivos y doctrinarios o, al menos, no sólo por ellos y que, más aún, suelen disimularse los verdaderos motivos que existen detrás de una decisión normativa o judicial, con argumentos eufemísticamente jurídico-técnicos y/o filosóficos.

Es que si se sabe poco sobre las instituciones y agencias estatales, sobre lo qué producen, sobre el personal que desempeña los roles decisorios en ellas y sobre las características de los conflictos en los que operan, no se sabrá qué cambiar para mejorarlas o, peor aún, basados en diagnósticos errados, sólo sustentados en intuiciones, creencias, impresiones, principios ideológicos o 
prejuicios de cualquier tipo, se promoverán reformas, acciones y decisiones que producirán efectos institucionales y sociales no queridos e imprevisibles ${ }^{6}$.

El Derecho constitucional y las disciplinas afines no son ajenas a estas preocupaciones. El estudio de la Constitución no puede ser entendido al margen de las teorías sobre el Estado, o ignorando el conocimiento sobre la producción de sus agencias e instituciones, y $\sin$ el auxilio inter y multidisciplinario de perspectivas politológicas y de sociología jurídica sobre los fenómenos en los que opera.

Resulta muy importante la generación de conocimiento y el análisis crítico de la jurisprudencia constitucional, como producto final del juicio de constitucionalidad de la actividad de los poderes públicos y los particulares y como referencia de interpretación y aplicación de la Constitución por los jueces, los cuales resultan actores principalísimos del proceso.?

La justicia constitucional en general y en España, en particular, a partir de la creación de la competencia jurisdiccional del Tribunal Constitucional (TC) afronta, entre otros, dos grandes campos de atribución y competencia y, por ende, de conflictos en los que interviene, relacionados a la descentralización que aquí nos ocupa.

En primer lugar, el conflicto político institucionalizado y extremo que, en rigor, implica el propio ejercicio del control de

6 En este sentido, MOLINELLI, Guillermo; PALANZA, Valeria y SIN, Gisela. Congreso, Presidencia y Justicia en Argentina. Materiales para su estudio, Temas, Buenos Aires, 1999, p. 21.

7 DE ESTEBAN, J. Curso de Derecho constitucional español III, Madrid, 1994, p. 28. 
la constitucionalidad, en especial el concentrado, que permite inhibir con efectos erga omnes los actos normativos de los otros poderes del Estado; dicho de otro modo, se inhiben las relaciones de poder y de conflicto entre la justicia constitucional, el Poder Legislativo y la presidencia. Además, el llamado "activismo judicial", el achicamiento del campo de las denominadas "cuestiones políticas no justiciables" y las características actuales de las tareas de hermenéutica e interpretación de los tribunales dificultan la consideración de la tarea de los tribunales constitucionales como la de un mero "legislador negativo".

La interpretación de la Constitución, a través de la jurisprudencia constitucional, siempre tiene carácter político, porque todo lo vinculado a ella y al Derecho constitucional es inevitablemente político, en tanto incorpora opciones de tal campo que suponen la elección de una vía por sobre otras posibles de atención y solución de conflictos, opciones que suelen tomarse por razones estrictamente de puja política o conveniencia social e institucional de oportunidad.

Además, los conflictos que se presentan ante el TC son, en especial en el caso del recurso de inconstitucionalidad y de los conflictos de competencia, disputas esencialmente políticas entre mayorías y minorías parlamentarias, o entre el Estado central y las CC.AA. (Comunidades autónomas) ${ }^{8}$. En suma, la jurisdicción constitucional refleja las tensiones y contradicciones políticas de la sociedad.

8 LÓPEZ GUERRA, Luis. Memoria de Cátedra, Universidad Carlos III, Madrid, p. 31. En el mismo sentido PÉREZ ROYO, J. Curso de Derecho Constitucional, Marcial Pons, Madrid, 1994, p. 26. 
Por otra parte, ello implica, una labor activa y creativa del TC impulsada por la ambigüedad de la Constitución y la existencia en ella de numerosas cláusulas generales, pues la CE contiene más cláusulas abiertas que cerradas, más valores y principios que reglas. ${ }^{9}$

En este sentido, se le atribuye al activismo del TC una labor de aplicación y validación de los principios y valores constitucionales, a través, de una tarea de recreación, adaptación y actualización a los nuevos conflictos y derechos que surgen. La Constitución es vista como un texto que alberga todas las respuestas, que deben ser buscadas y objetivadas por el $\mathrm{TC}^{10}$.

En segundo lugar, el papel fundamental que la justicia constitucional desempeña en la construcción y consolidación de la organización y distribución territorial del poder en Estados descentralizados o que se encuentran en vías de un proceso de descentralización, una cuestión de alta relevancia en España con el proceso de desarrollo estatutario de las autonomías, que presenta escenarios de alta complejidad y conflictividad política ${ }^{11}$.

Especialmente en España se previó una justicia constitucional concentrada, según la tradición europea, que, además, sería necesaria para organizar al Estado descentralizado y resolver sus

ARAGÓN REYES, Manuel. Constitución y Democracia, Tecnos, Madrid, 1989, pp. 91 - 97.

DÍAZ REVORIO, Javier. La Constitución como orden abierto, Mc Graw-Hill, 1997, y también Valores superiores e interpretación constitucional, CEPC, Madrid, 1997.

11 Seguimos en estos lineamientos el planteo de JAVIER DÍAZ Revorio en su material de presentación de los cursos de especialización en Justicia Constitucional, UCLM, campus de Toledo, 2006, mimeo. 
conflictos territoriales de competencia y, más aún, cooperar en la organización territorial sólo prevista superficialmente por la CE pero no realizada por ella ${ }^{12}$.

Y, además, puede decirse que se ha llegado al punto actual del desarrollo autonómico, merced a la labor del TC, dada la escasa configuración constitucional en la materia y las ambigüedades de los estatutos de autonomía. El TC ha delimitado competencias arduamente y ha sido muy eficaz para encaminar y articular la compleja distribución territorial del poder que se discute en España $^{13}$. Pero el TC, a pesar de esa valoración positiva que existe en la doctrina y que ha demostrado con su jurisprudencia, se encuentra en constante tensión y en medio de pujas de alta conflictividad política, que han dañado su credibilidad y legitimidad social. Su virtud inicial se ha ido transformando en defecto a la vista de vastos sectores de la sociedad. Es que la gran incógnita radica en cuestionarse hasta dónde el TC puede propender al desarrollo autonómico, si éste avanza cada vez más en las exigencias de competencias básicas, vaciando de las mismas al Estado central, hasta rozar concepciones soberanistas e independentistas. No debe perderse de vista que el TC abreva su legitimidad y legalidad en la CE como norma fundamental del Estado español. Allí, en la matriz y estructura lógica de su autoridad y poder se encuentran sus propios límites y hasta su propia supervivencia como autoridad competente.

12 En este sentido, ARAGÓN REYES, Manuel, “25 años de justicia constitucional en España", Revista Iberoamericana de Derecho Procesal Constitucional, N. ${ }^{\circ}$, Ed. Porrúa, México, 2004, p.6.

Ibídem, p. 10. 


\section{EL TRIBUNAL CONSTITUCIONAL ESPAÑOL Y EL DESARROLLO AUTONÓMICO A TRAVÉS DEL CONTROL DE CONSTITUCIONALIDAD}

Suele resultar inconducente extralimitarse en el uso y la definición de conceptos teóricos y tipos ideales de clasificación, según la tipología "weberiana", si no se confrontan esos desarrollos prescriptivos con el devenir efectivo de los hechos, a través de la utilización de variables empíricas que permitan explorar, describir y entonces, por fin, comprender cómo están funcionando las relaciones institucionales de un Estado.

Un buen ejemplo de tal debate estéril lo da la discusión sobre la organización política del territorio que ocurre en muchos países, discutiendo su carácter federal, unitario o más o menos centralizado o descentralizado, sin observar y desagregar con detenimiento cómo funcionan las relaciones entre los distintos niveles estatales de gobierno. Las categorías conceptuales que se superponen de modo difuso son inconducentes para comprender una realidad compleja y particular como la del sistema español, si no son complementadas con datos de conocimiento básico que permitan establecer por dónde pasan los vectores de la organización territorial del Estado.

George ANDERSON, experto en federalismo, durante varios años presidente del Forum of Federations y buen conocedor del sistema político y jurídico español, considera a España un país con características federales, y sostiene que un observador desprevenido lo consideraría federal sin dudarlo, a pesar de que tal denominación es evitada en la propia España por razones políticas, históricas y culturales ${ }^{14}$.

\footnotetext{
14 ANDERSON, George. Federalism: An Introduction, Oxford University Press, Canada, p. 4.
} 
También sostiene que España, por las competencias delegadas a las CC.AA., o por el nivel de tributos que capta el gobierno central podría asemejarse a distintos modelos de países que se reivindican como federales ${ }^{15}$.

Según Anderson existen dos modelos de distribución constitucional de competencias: el dualista y el integrado. El dualista (los casos, por ejemplo, de Argentina, Brasil, Canadá o EE.UU.) otorga competencias distintas a la federación y a las unidades subnacionales. En cambio, el integrado (Alemania, Austria, España) otorga muchas competencias concurrentes que se superponen en cuanto a la materia entre la entidad estatal y la subestatal $^{16}$.

Un ejemplo de ello resultan los artículos 148.1 y 149.1 de CE, que otorgan competencias a las CC.AA. y al Estado nacional muchas veces sobre materias similares, por ello se trata de competencias concurrentes. El diseño usual otorga al Estado nacional los lineamientos, ordenación y legislación básica, mientras que a las CC.AA. les corresponden la ejecución, implementación y legislación específica.

Así habrá materias de competencias exclusivas reservadas íntegramente al Estado; materias en los que los Estatutos de autonomías (EEAA) reservan éstas a las CC.AA.; finalmente, hay una amplia lista de materias y competencias compartidas en las que, en virtud de la CE y de los EEAA, tanto el Estado como las CC.AA. ostentan funciones y competencias en distintos niveles. Se trata de materias relevantes como la sanidad y la educación,

\footnotetext{
15 Ibídem, pp. 33 - 34.

16 Ibídem, p. 16.
} 
entre otras. El sistema, así compartimentado, resulta muy complejo y presenta distintas modalidades, en las cuales pueden existir una división de funciones legislativas para el Estado y ejecutivas para las CC.AA. en la misma materia, o aún compartir funciones legislativas por ambas entidades en la misma materia.

El modelo constitucional de federalismo "integrado", con muchas competencias concurrentes, hace que ellas sean más difusas, generando conflictos por la delimitación de las mismas. Por ende, tomando como ejemplo el caso español, el TC debe asumir una actividad intensa y un rol muy activo, mayor del que generalmente debe asumir un alto tribunal para resolver conflictos de competencia en federaciones de modelo "dualista".

Se ha dicho que "el Estado autonómico, generado por la Constitución de 1978, y configurado durante más de tres décadas, aparece por tanto como una forma de descentralización política importante, que otorga a las CC.AA. un volumen de poder equivalente a los Länder o Estados de sistemas federales, pero sin manifestar un carácter jurídico claro"17.

AnDERSOn y también el reconocido Ronald WatTs tienen una perspectiva muy amplia y acogedora del federalismo, y por esa inteligencia admiten, prácticamente, que cualquier experiencia más o menos descentralizada implica algún tipo o grado de federalismo. Entiendo que así se le hace un flaco favor a su militancia pro-federalista. La difusa delimitación y precisión de la categoría conceptual, y su supuesta o pretendida adaptabilidad o flexibilidad, generan una idea laxa y poco rigurosa que no

17 AJA, Eliseo. Estado autonómico y reforma federal, Alianza Editorial, Madrid, 2014, p. 16. 
ayuda al debate científico. Es lo que sostuvo el recientemente fallecido Ortega Alvarez, en su crítica a la expansión de la denominación federal a cualquier sistema político que presente algún rasgo federalizante ${ }^{18}$.

En esa línea WatTs admite que los conceptos "federal" o "federación" y/o derivados, no se mencionan ni una sola vez en la $\mathrm{CE}$ ni en las disposiciones legislativas reglamentarias. Aún así, sostiene que España presenta características típicas de federalismo, y agrega un listado con alrededor de diez doctrinarios españoles que, con matices y voluntarismo, sostienen que existe federalismo en España ${ }^{19}$.

Hay juristas, como el fallecido magistrado del TC, Luis Ortega Álvarez, o Solozábal Echavarría que son críticos o escépticos en calificar de federal al Estado español; otros, como Tudela ARANDA, son muy prudentes al analizar el estado de las autonomías y a ver en él atisbos de federalismo, en especial por las asimetrías y heterogeneidades observables en el momento actual del desarrollo del proceso autonómico.

Por esta dispersión de opiniones y enfoques, resulta menester, una vez más, producir conocimiento más objetivo, riguroso y microscópico, que permita acercarse a lo nodal del proceso y comprenderlo con más sofisticación, no solamente desde posiciones en exceso "generalistas". Manuel Giménez Abad - CEPS, Madrid, 2010, pp. 91 y ss. 
Al hablar de conflictos de competencia y recursos de inconstitucionalidad en los que confrontan los órganos legitimados por el Art. 162.1.a CE ante el TC, se sobreentiende que se está hablando de problemas políticos entre el Estado nacional y las CC.AA. Incluso, la judicialización ha llevado a una actividad intensa por parte de los jueces ordinarios y en especial los autonómicos, a través de la introducción de cuestiones de inconstitucionalidad.

Se le critica desde las CC.AA. al TC la aplicación de criterios centralistas, lo que más allá de compartir o no el criterio, no puede resultar sorpresivo, siendo una institución producto de la CE y del diseño institucional del Estado nacional, e implicando su acción e interpretación la última palabra constitucional, por tanto, de gran influencia.

Las críticas más relevantes al TC son:

1. El papel del TC es fundamental en la distribución del poder del Estado y el alcance de sus competencias y, además, la CE le permite lecturas diversas dada la ambigüedad con que trata el tema sobre competencias.

2. El legislador estatal promueve el centralismo y la uniformidad de la distribución de las competencias y el TC ha seguido la misma línea.

3. El TC puede cambiar ese sesgo, mediante una interpretación pro-autonómica, siendo que la CE y los Estatutos autonómicos permiten interpretaciones evolutivas y amplias en ese sentido.

4. El TC ha sostenido una jurisprudencia contradictoria y sinuosa en la materia. 
5. Debe modificarse el sistema de elección de los Magistrados, dando cabida a las nacionalidades.

6. El retraso de las sentencias del TC unido a los efectos del Art. 161.2 CE retarda la entrada en vigor de las normas autonómicas impugnadas.

Este listado de impugnaciones lleva a la conclusión, desde el campo crítico y pro-autonómico, que el TC junto al legislador son instituciones que promueven el centralismo ${ }^{20}$.

Sin embargo, veremos que ha existido una conducta institucionalista por las propias CC.AA., quienes han hecho uso intenso de las vías procesales que la CE dispone para la delimitación de competencias y el desarrollo del proceso autonómico.

Las tareas del TC deben estar dirigidas a conseguir la máxima funcionalidad del sistema autonómico, no obstante ser una institución clave del diseño institucional del Estado nacional. La naturaleza política de las controversias que resuelve le obligan a proveer desde una óptica que tenga en consideración el principio de previsibilidad y anticipación respecto de las consecuencias de sus sentencias, sin dejarse llevar por construcciones dogmáticas poco realistas o por teorías puristas.

En ese sentido, se le ha reconocido al TC y ha sido proclamado por varios de sus presidentes la tarea fundamental de la institución en

20 Hemos seguido para este listado a AJA Eliseo y PÉREZ TREMPS Pablo. "Tribunal Constitucional y organización del estado autonómico", en ESPÍN, Eduardo y DÍAZ REVORIO, Javier (coords.), La justicia cosntitucional en el estado democrático, Tirant Lo Blanch, Valencia, 2000, pp. 146 y 147. 
procura del desarrollo y construcción de las autonomías, proceso que la CE ha dejado abierto.

No obstante la contribución del TC al desarrollo de las autonomías, las definiciones venideras, cada vez más complejas y profundas y, por tanto, con una mayor dosis de politicidad, deberían ser afrontadas, en mayor medida, por las instituciones políticas, evitando un exceso de judicialización que dañará irremediablemente al TC por la desnaturalización de sus funciones. El TC ha sido vital en el avance del proceso de descentralización $\mathrm{y}$, en todo caso, sus injerencias criticadas se deben a la ineficacia de los órganos políticos en resolver las cuestiones, y/o a la propia demanda que desde ellos se le hace a la institución. A esta altura, el TC sólo debe asegurar que las fórmulas y soluciones que se aporten desde los órganos políticos se encuentren dentro del marco constitucional y, en su caso, delimitar el avance de esas fórmulas.

Desde una perspectiva politológica, en este escenario donde debe dirimir conflictos el TC se entrecruzan diversas variables extrajurídicas: el tradicional centralismo español; las particularidades históricas, culturales y linguiísticas de muchas comunidades dentro del territorio del Estado central; el enunciado del Art. 2 de la CE que consagra la unidad indisoluble de la nación española, catalogándola de patria común e indivisible de todos los españoles, y reconociendo, además, el derecho a la autonomía de nacionalidades y regiones. Todo ello también delimitado por las resistencias a avanzar en una organización de tipo federal, pues la autonomía no reconoce soberanía, y aún las soberanías sujetas a la supremacía del Estado federal son vistas con recelo en el diseño institucional español. Diseño que, a su vez, deja indefinido el modelo de organización territorial adoptado. Todo 
ello da como resultado un proceso autonómico en expansión desde su instauración, a partir de la sanción de la CE en 1978 y del funcionamiento pleno del Estado de derecho, con un final abierto y complejo en relación a cuál será el límite del desarrollo autonómico y su sujeción a la unidad española. Resulta ser una lección básica en ciencia política que el otorgamiento de un derecho a la autonomía en razón de particularidades históricas, lingüísticas y culturales que involucran nacionalidades y regiones (en sentido cultural-antropológico que remite a territorios, características típicas y costumbres) presentará dificultades de obturación una vez iniciado y reconocido. Prueba de ello es que la CE no impone la autonomía, sino que la presenta como un derecho que puede o no ser ejercido. Sin embargo, luego de más de tres décadas de constitucionalización, el proceso autonómico se ha generalizado de modo tal que abarca todo el territorio español. Además, cada logro autonómico alcanzado por alguna CC.AA., es inmediatamente situado como meta u objetivo político por las demás CC.AA., lo que hace que el proceso permanezca sumamente abierto y con una dinámica impensada e imprevisible, más aún en el actual marco de desarrollo, a su vez, del proceso regional supranacional de la Unión Europea. También ayudan a extremar la complejidad del escenario las ambigüedades de la $\mathrm{CE}$ en la conceptualización de los derechos otorgados a categorías como nacionalidades y regiones, las que pueden aparecer, incluso, como teóricamente redundantes.

Además de las complejidades de diseño constitucional, puesto que el reparto de competencias entre el Estado y las CC.AA. no se efectúa directamente o solo a través de la $\mathrm{CE}$, dicho reparto se completa a través de los estatutos autonómicos y, excepcionalmente, a través de otras normas a las cuales la CE y los estatutos remiten. 
A ese conjunto normativo se lo denomina "bloque de constitucionalidad". El TC entonces, al resolver estos conflictos, debe aplicar para la interpretación del caso todo el bloque de constitucionalidad $^{21}$.

La conflictividad entre el Estado y las CC.AA. ha sido una característica típica del desarrollo autonómico en España, con intervenciones jurisprudenciales del TC que han sido cuantitativamente muy superiores a las producidas en otros sistemas políticos europeos, por ejemplo, Alemania e Italia, llegando a conformar una especie de Estado jurisprudencial autonómico, denominación que pretende graficar la decisiva intervención de la jurisprudencia del TC para encauzar el desarrollo de las autonomías ${ }^{22}$.

\section{EL TC Y LAS CC. AA.}

\section{EI TC y su performance en relación a las CC.AA.}

En pos del conocimiento más objetivo, riguroso y microscópico, que permita acercarse a lo nodal del proceso y comprenderlo con más sofisticación, que he reclamado supra, veremos y analizaremos datos sobre la performance del TC en relación a los conflictos judiciales, donde ha ejercido el control de la constitucionalidad y que involucraron a las CC.AA. Los datos y estadísticas vertidos en este artículo pueden verse con más

21 Seguimos en este esquema a PÉREZ TREMPS, Pablo. Derecho Constitucional, El Tribunal Constitucional, Vol. II, Tirant lo Blanch, Valencia 2003, pp. 243 - 287. 
desagregación en la investigación mayor de la cual se extraen las referencias ${ }^{23}$.

El TC emitió mayor cantidad de sentencias sobre normas nacionales, pero declaró proporcionalmente más inconstitucionalidades sobre normas autonómicas. El hallazgo es absolutamente consistente y por demás interesante, presentando varias líneas de análisis que arrojan conclusiones sólidas.

El TC emitió un 69\% de las sentencias sobre control de constitucionalidad sobre normas nacionales (824 casos), y un 31\% (363 casos) sobre normas autonómicas. Esta mayor actividad del TC sobre normas nacionales es una pauta objetiva que demuestra que la conflictividad constitucional es mayormente nacional, pues la legislación nacional es vital y más común, numerosa y abarca la mayoría de las áreas conflictivas más trascendentes de la sociedad española. A su vez, también es indicativa de que las competencias administrativas permanecen, fundamentalmente,

BERCHOLC Jorge O., La performance del Tribunal Constitucional español a través del ejercicio del Control de Constitucionalidad de los actos normativos de los otros poderes políticos del Estado (1980-2011). Un estudio sobre las relaciones entre el Tribunal Constitucional y el sistema político-institucional de España; proyecto de investigación UBACyT, acreditado por la Universidad de Buenos Aires, Secretaría de Ciencia y Técnica, convocatoria 2010/2012 y 2013/2016, N. ${ }^{\circ}$ Proyecto 20020120100031, Resolución N. ${ }^{\circ}$ 6932/13, Director del proyecto Jorge O. Bercholc, “Un estudio comparado de la performance de los Tribunales Constitucionales de la Argentina, Alemania, Canadá, España y Brasil en el ejercicio del Control de Constitucionalidad". Todos los datos estadísticos vertidos en este artículo son extraídos de la investigación aquí referida. El trabajo se halla en estado de edición, en la Argentina por editorial EDIAR, y en España por la editorial Tirant Lo Blanch. En ambos casos de próxima aparición. 
en manos de las agencias del Estado central. Refuerza esta conclusión que el $73 \%$ de las sentencias sobre normas de jurisdicción nacional se emiten en el marco de cuestiones de inconstitucionalidad, es decir, en pleitos entre justiciables originados ante el poder judicial ordinario. Solo el $22 \%$ se emite en recursos de inconstitucionalidad incoados por los habilitados por la legitimación restringida del artículo 162.1.a de la CE. El 5\% restante se origina en conflictos positivos de competencia (cuadro $\left.N .^{\circ} 1\right)$.

Asimismo, las declaraciones de inconstitucionalidad de normas autonómicas son, proporcionalmente, casi el doble que para las nacionales. El TC declara inconstitucionalidades en un $36 \%$ de los casos sobre normas autonómicas (160 decisiones) y en un 19\% (176 decisiones) de los casos sobre normas nacionales.

Los datos expuestos muestran que el TC, en modo inversamente proporcional a la mayor cantidad de casos en los que se cuestiona a las normas nacionales, declara más inconstitucionalidades de normas autonómicas. Así, el TC se muestra más activo en declarar inconstitucionalidades de normas autonómicas que de normas nacionales.

Además, el $64 \%$ de las sentencias sobre normas de jurisdicción autonómica se emiten en el marco de recursos de inconstitucionalidad, incoados a través de los órganos políticos legitimados por el artículo 162.1.a CE, a contra sensu a lo que se observa en la jurisdicción nacional. También permite corroborar que la conflictividad constitucional en normas de jurisdicción autonómica está fuertemente influenciada por la puja política y sobre competencias entre las CC.AA. y el Estado central. Solo el $28 \%$ de las sentencias del TC sobre normas autonómicas se emite ante cuestiones de inconstitucionalidad (cuadro $N .^{\circ} 1$ ). 


\section{Cuadro N. 1}

\begin{tabular}{|c|c|c|c|}
\hline \multicolumn{4}{|c|}{$\begin{array}{c}\text { Total y porcentual de sentencias emitidas por el TC } \\
\text { desagregadas por jurisdicción y por vía procesal }\end{array}$} \\
\hline Sentencias sobre: & CUESTIÓN & RECURSO & CONF. COMPETENCIA \\
\hline NORMAS NACIONALES & $44(5 \%)$ \\
\hline Total: 824 & $596(73 \%)$ & $184 \quad(22 \%)$ & $41 \quad(8 \%)$ \\
\hline NORMAS AUTONÓMICAS & $150 \quad(28 \%)$ & $343 \quad(64 \%)^{(1)}$ & \\
\hline \multicolumn{3}{|c|}{ Total: 534} & (1) Se incluyen las 174 suspensiones resueltas en recursos de inconstitucionalidad. \\
\hline \\
Fuente: Elaboración propia, de acuerdo a base de datos construida, extrayendo \\
información de autos y sentencias de la web-page del TC.
\end{tabular}

Y para verificar, aún con más consistencia, el complejo cuadro de la situación competencial que afronta el TC, obsérvese que las inconstitucionalidades autonómicas han sido declaradas en un $82 \%$ en recursos de inconstitucionalidad y conflictos de competencia, y sólo en un $18 \%$ ante cuestiones de inconstitucionalidad, performance que resulta fiel reflejo de quienes y a través de cuales vías procesales originan la actuación de la jurisdicción constitucional (cuadro N. ${ }^{\circ}$ ). 


\section{Cuadro N. 2}

\begin{tabular}{|l|c|c|c|}
\hline \multicolumn{4}{|c|}{ Totales y porcentuales de inconstitucionalidades según recurso y } \\
desagregado por jurisdicción
\end{tabular}

Fuente: Elaboración propia, de acuerdo a base de datos construida, extrayendo información de autos y sentencias de la web-page del TC.

\section{Análisis desagregado del conflicto entre el Gobierno y las CC.AA. más reivindicativas. Particularidades del caso de Cataluña}

El País Vasco y Cataluña, como es sabido, son las CC.AA. más conflictivas en su relación con el Estado central y reivindicativas de sus competencias y su autonomía. Las estadísticas no hacen más que confirmar la especie. Pero lo que resulta de interés son las diversas desagregaciones que permiten identificar con más certeza las características de los conflictos entre las CC.AA. y el Gobierno nacional que se ventilan ante el TC.

País Vasco y Cataluña son las CC.AA. que han sufrido mayor cantidad de declaración de inconstitucionalidades. Ello se verifica considerando las dos unidades de análisis utilizadas, las normas y las decisiones -autos y sentencias-. 
Han sido declaradas 30 y 29 normas inconstitucionales vascas y catalanas respectivamente, luego sigue Galicia con 14 , menos de la mitad de normas inconstitucionales de las dos primeras CC.AA. del ranking. Siguen en el orden del ranking las CC.AA. insulares, Baleares y Canarias.

Considerando la unidad de análisis decisiones, si bien Cataluña y el País Vasco son, previsiblemente, las CC.AA. a las que en más ocasiones se les han declarado normas propias inconstitucionales, otras CC.AA., por ejemplo Galicia, Baleares, Aragón, Asturias, Cantabria, presentan porcentuales superiores pero en cantidades nominales mucho menores de casos.

También considerando decisiones, el País Vasco y Cataluña se diferencian claramente del resto de las CC.AA., por la mayor cantidad en que fueron cuestionadas sus normas. El País Vasco y Cataluña tuvieron casi un centenar de autos y sentencias del TC en que fueron cuestionadas sus normas autonómicas. La CC.AA. que sigue es Canarias con 50 procesos.

Se han detectado algunas particularidades, muy interesantes y sugestivas, que merecen análisis cualitativos más desagregados. En el caso de Cataluña se observa que sus normas autonómicas han sido cuestionadas mayoritariamente por vía del recurso de inconstitucionalidad, siendo mucho menos relevante, en términos comparados, la cuestión de inconstitucionalidad que para el resto de las CC.AA.

De un total de 98 resoluciones en las que se han cuestionado normas catalanas, el $71 \%$ se emitieron ante recursos de inconstitucionalidad; el País Vasco con 97 resoluciones sobre sus normas y Canarias con 50, presentan un $47 \%$ y un $54 \%$, 
respectivamente, de resoluciones ante planteos de recursos de inconstitucionalidad.

Estos datos, muy consistentes y descriptivos de ese sesgo, requieren de hipótesis explicativas cualitativas. ¿Acaso los jueces del poder judicial ordinario, en especial los catalanes, han tenido una performance muy prudente respecto a cuestionar las normas catalanas ante el TC? ${ }^{24}$

Tal vez ello ha generado que la conflictividad competencial y política entre el Gobierno nacional y Cataluña se canalice especialmente a través del TC, lo que explicaría ese alto porcentaje de recursos de inconstitucionalidad (con legitimación activa restringida, según Art. 162.1.a CE) cuestionando normas catalanas.

También se puede conjeturar que las normas catalanas no han despertado, en los jueces ordinarios, dudas sobre su constitucionalidad, en la proporción en que sí han sido cuestionadas por los órganos políticos a través del recurso de inconstitucionalidad. Esto nos lleva a esgrimir la hipótesis de que existe una fuerte judicialización del conflicto político entre el Gobierno y Cataluña, lo cual en sí mismo no es una gran novedad, pero que sí arroja una lectura con datos más desagregados y conducentes para una lectura más microscópica y certera del problema, si consideramos las estadísticas vertidas sobre Cataluña comparadas con el resto de las CC.AA. Ellas muestran una judicialización mucho mayor que, incluso, el conflicto vasco;

24 Dado que deberían ser los jueces ordinarios catalanes los que tendrían que efectuar la consulta al TC, ante dudas constitucionales sobre las normas autonómicas de aplicación en Cataluña. 
y que esa judicialización ha sido impulsada principalmente por los órganos políticos más que por el poder judicial ordinario.

Fortalece esta hipótesis, el revés de la trama del conflicto, puesto que Cataluña ha cuestionado normas nacionales en nada menos que 195 procesos, más del doble de los procesos que impulsaron las instituciones vascas, sólo 78, aunque superior al resto de las CC.AA.

Más aún, el 69\% de esos procesos impulsados por instituciones catalanas fueron a través de cuestiones de inconstitucionalidad (135 planteos), el 84\% de ellas contra normas nacionales aunque en contadas ocasiones, sólo 7 procesos, el TC declaro inconstitucionalidades nacionales por esta vía por impulso de tribunales catalanes-. Lo que indica que los jueces del poder judicial catalán han sido muy activos en las consultas sobre inconstitucionalidad de normas nacionales, a contra sensu de su actividad ante las normas propias de Cataluña. También los órganos políticos catalanes han sido más activos que el resto de sus pares autonómicos, mostrando la mayor cantidad de interposición de recursos de inconstitucionalidad, 39, seguido por el País Vasco con 26.

Otras dos variables que fortalecen estas hipótesis son:

1) Las suspensiones del Art.161.2 $\mathrm{CE}$ han sido, para el caso de Cataluña, el doble de las que se han contabilizado para el País Vasco, ambas CC.AA. con cifras similares de procesos en los que se cuestionan normas de dichas autonomías. Recuérdese lo ya expuesto, el procedimiento de suspensión permite, más allá del debate sobre la cuestión jurídica de 
fondo, un éxito relativo inmediato para el Gobierno, el de la inhibición de los efectos y la operatividad de la norma cuestionada. Ello sumado a las demoras que, en ocasiones, pueden contarse en años, para la resolución sobre la cuestión de fondo.

2) Las inconstitucionalidades de normas catalanas decretadas por el TC son, proporcionalmente, mayores que para el País Vasco, única CC.AA. con guarismos nominales parecidos a Cataluña en relación al cuestionamiento de sus normas autonómicas. También son notoriamente mayores, en términos nominales, que para el resto de las CC.AA, las que presentan una cantidad notablemente menor de procesos que cuestionen normas autonómicas de cada una de ellas.

Todo lo expuesto nos lleva a sustentar una hipótesis que, sin perjuicio de requerir análisis cualitativos más desagregados y correlacionados con otras variables, parece suficientemente consistente.

El conflicto político-competencial-jurídico-constitucional entre el Gobierno nacional y Cataluña se ha judicializado, notoriamente, por una serie de acciones de ambos actores. Y se ha judicializado en medida mayor que cualquier otro conflicto entre el Gobierno nacional y las CC.AA., incluso el que involucra al País Vasco, que parece transitar por canales más políticos que jurídicos, al menos en comparación a las opciones catalanas.

Se sustenta la hipótesis, de acuerdo a lo visto en este apartado en que:

1) Cataluña es la CC.AA. que tiene la mayor cantidad de normas declaradas inconstitucionales por el TC; 
2) Es la CC.AA. que ha sufrido más cantidad de suspensiones de normas de acuerdo al procedimiento del Art. 161.2 CE;

3) Es la CC.AA. que ha interpuesto mayor cantidad de recursos de inconstitucionalidad contra normas nacionales, lo que implica intensa actividad de los órganos políticos legitimados por el Art. 162.1.a CE;

4) También los jueces del poder judicial ordinario en Cataluña han sido muy activos interponiendo cuestiones de inconstitucionalidad ante el TC respecto de normas nacionales; $y$,

5) A contra sensu, los jueces del poder judicial ordinario en Cataluña han sido muy poco activos en la interposición de cuestiones de inconstitucionalidad ante el TC respecto de normas autonómicas.

Lo expuesto nos lleva a esgrimir otra hipótesis sólida de tipo secundario en el marco de la judicialización del conflicto entre el Gobierno y Cataluña. El Gobierno basó su estrategia en la actividad del TC vía recursos de inconstitucionalidad y el uso de lo dispuesto por el Art.161.2 CE. Cataluña también fue activa en el uso del TC vía recursos de inconstitucionalidad, pero con una actitud del poder judicial ordinario en Cataluña muy sugestiva, hiperactiva en plantear ante el TC cuestiones de inconstitucionalidad sobre normas nacionales, y muy pasiva en hacerlo sobre normas de la propia Cataluña.

Estas evidencias pueden ser consideradas positivamente puesto que, en dicha valoración, los conflictos políticos son canalizados por vías jurídicas e institucionales evitando confrontaciones más extremas y/o basadas en la violencia política. 
La ponderación negativa es que la juridificación de conflictos de alto voltaje político pone en aprietos a las instituciones jurisdiccionales por las severas dificultades objetivas de posibilidad para operar eficazmente en ese ámbito. Además, la política reniega, en ese escenario, de su ámbito de acción natural y judicializa procesos de toma de decisiones, situándolos en un territorio que es ajeno a la propia naturaleza de los conflictos y decisiones en pugna, tornando ineficaz la acción y poniendo en crisis la legitimidad de los órganos jurisdiccionales.

\section{Misceláneas entre el TC, las CC.AA. y el Gobierno}

1) Una aclaración adicional que resulta pertinente respecto a la hipótesis anterior: sólo aproximadamente en el 10\% de las cuestiones de inconstitucionalidad interpuestas ante el TC sobre normas nacionales, éste decreto la inconstitucionalidad de las mismas en cuestiones impulsadas por los tribunales autonómicos, siendo que tribunales de las CC.AA. impulsaron en el $71 \%$ las cuestiones sobre normas nacionales. Esto implica que en general el TC ha sido restrictivo en declarar inconstitucionalidades por la vía procesal de las cuestiones de inconstitucionalidad, vía mayoritariamente utilizada por tribunales con sede en las CC.AA.

2) El País Vasco proporcionalmente, y Cataluña nominalmente, son las CC.AA. que han logrado con más suceso, la declaración de inconstitucionalidades por el TC cuando han impulsado el cuestionamiento de normas. Sus porcentuales de éxito en los procesos en los que cuestionaron normas fueron del 28\% y $19 \%$ respectivamente. Sin embargo, si se desagregan las inadmisiones, que fueron muchas en el caso de Cataluña (42\%), y se observa que dicha CC.AA. en los recursos obtuvo declaraciones de 
inconstitucionalidad sobre normas nacionales en un $69 \%$ de los que interpuso $(27 \mathrm{~s} / 39)$ y en un $52 \%$ de los conflictos de competencia incoados (11 s/ 21), vemos que Cataluña ha tenido una exitosa performance judicial en sus conflictos con el Gobierno nacional. Ello se verá reflejado luego, al comentar lo que surge del análisis por ICEA, donde Cataluña tiene la mejor performance, excluyendo la gran cantidad de cuestiones de inconstitucionalidad que sus tribunales han planteado ante el TC con muy escasos éxitos.

También en esta variable, cuando las CC.AA. cuestionaron normas, otras CC.AA., por ejemplo Galicia, Baleares, Extremadura, Cantabria, presentan porcentuales superiores pero en cantidades nominales mucho menores de casos incoados.

3) Todas las CC.AA. han tenido declaraciones de inconstitucionalidad de sus normas, mayoritariamente, en materia administrativa $y$, en mucha menor medida sobre normas de materia comercial. Sobre 162 normas autonómicas declaradas inconstitucionales 115 fueron de materia administrativa, el $71 \%$ del total. Las de materia comercial fueron 22, son las únicas dos materias en las que hubo más inconstitucionalidad de normas autonómicas que nacionales. Se reproduce el cuadro N. ${ }^{\circ}$, que desagrega las normas autonómicas de materia administrativa declaradas inconstitucionales ${ }^{25}$.

25 Los datos son extraídos de los cuadros estadísticos de la investigación referida. 


\section{Cuadro N. 3}

\begin{tabular}{|l|c|}
\hline \multicolumn{2}{|c|}{$\begin{array}{c}\text { Desagregado de normas administrativas autonómicas } \\
\text { declaradas inconstitucionales }\end{array}$} \\
\hline Ambientales/pesca/urbanísticas & 21 \\
\hline Función pública & 10 \\
\hline Presupuestos generales. & 9 \\
\hline Policías locales & 7 \\
\hline Radiodifusión y TV & 7 \\
\hline Lingüísticas & 5 \\
\hline $\begin{array}{l}\text { Bases locales } \\
\text { Cajas de ahorro y cooperativas }\end{array}$ & 5 \\
\hline $\begin{array}{l}\text { Varios } \\
\text { * En este rubro aparecen normas sobre: tasas, sector eléctrico, transportes terrestres, } \\
\text { ordenación farmacéutica, bibliotecas, tributarias, regulación de la justicia, regulación } \\
\text { del comercio, competencias de diputaciones provinciales. }\end{array}$ \\
\hline $\begin{array}{l}\text { 1 Se desagregan dentro de la materia administrativa los campos o temas en los que se } \\
\text { agrupan las normas autonómicas declaradas INC. }\end{array}$ \\
\hline
\end{tabular}

4) Desde la Comunidad de Madrid se han cuestionado normas en 74 procesos, sólo una vez se impulsó un recurso de inconstitucionalidad, esto es que los órganos políticos autonómicos de Madrid no han cuestionado prácticamente normas nacionales. El resto de los 73 procesos fueron cuestiones de inconstitucionalidad interpuestas por tribunales madrileños.

5) Los cuadros estadísticos de la investigación referida presentan un ranking por índice de conflictividad y éxito autonómico 
(ICEA) desagregado por CC.AA., considerando las decisiones del TC que involucran a CC.AA. ${ }^{26}$.

El ranking presenta a Andalucía y al País Vasco, como las CC.AA. con mejor performance considerando todas las variables reflejadas y computadas para la construcción del ICEA.

Otro cuadro refleja un ranking con el mismo ICEA, pero sin considerar las cuestiones de inconstitucionalidad, lo que permite hacer una comparación directa con la performance del Gobierno nacional, del que se obtiene el ICEA de acuerdo a su performance desagregada en sus propios cuadros estadísticos.

En este caso, el cuadro, excluidas las cuestiones de inconstitucionalidad, muestra que la performance, según ICEA, de Andalucía y País Vasco lucen muy desmejoradas, indicador de que sus políticas judiciales ante el TC les ha sido más bien desfavorables, pues este dato se basa en los resultados de los

26 El índice refleja el grado de éxito alcanzado por las CCAA de acuerdo a las resoluciones dictadas por el TC considerando todos los procesos judiciales por control de constitucionalidad en que la respectiva CCAA estuvo involucrada. A efectos de la construcción del índice se han considerado las siguientes variables: i) total de decisiones recaídas en los casos en que las normas autonómicas fueron impugnadas; ii) decisiones por la Constitucionalidad y la inadmisión en esas mismas resoluciones pues estas se consideran un éxito para la CCAA involucrada ya que la norma autonómica impugnada supera el test de constitucionalidad; iii) total de decisiones recaídas_en los casos en que las CCAA cuestionaron normas; iv) decisiones por la Inconstitucionalidad en esas mismas resoluciones pues estas se consideran un éxito para la CCAA involucrada ya que la norma nacional impugnada por la CCAA fue declarada inconstitucional. Para más detalles véanse los cuadros estadísticos de la investigación referida. 
procesos donde los órganos políticos son los únicos legitimados activos (Art. 162.1.a CE).

Del entrecruzamiento de las distintas variables reflejadas en los cuadros, se observa en el ranking del cuadro N. ${ }^{\circ} 4$, que Cataluña, excluyendo las cuestiones de inconstitucionalidad -en la que los jueces catalanes se han mostrado muy activos en consultas al TC respecto de normas nacionales que, provoca una muy escasa y restrictiva recepción por parte del TC- tiene el mejor índice de éxitos considerando las variables computadas, con una diferencia notoria respecto a las demás CC.AA. Además es también la CC.AA. que muestra la mayor actividad judicial ante el TC, de una intensidad muy superior en relación al resto de las CC.AA., incluso al País Vasco. El índice refleja un coeficiente que relaciona los éxitos y la densidad e intensidad de la actividad judicial ante el TC en pos de dirimir los conflictos que involucran al Gobierno y a las CC.AA. Ello implica que la judicialización del conflicto le ha significado a Cataluña un relativo éxito, en términos comparados al resto de las CC.AA., en su puja políticocompetencial-jurídico-constitucional con el Gobierno nacional. 


\section{Cuadro N. ${ }^{\circ}$}

\begin{tabular}{|c|c|c|c|c|}
\hline \multicolumn{5}{|c|}{$\begin{array}{l}\text { Ranking por índice de conflictividad y éxito autonómico (ICEA) } \\
\text { desagregado por CC.AA., considerando solo recursos de } \\
\text { inconstitucionalidad y conflictos de competencia }{ }^{(1)}\end{array}$} \\
\hline \multicolumn{5}{|c|}{ ÍNDICE DE CONFLICTIVIDAD Y ÉXITO AUTONÓMICO } \\
\hline \multirow[t]{2}{*}{ COMUNIDAD } & \multicolumn{2}{|c|}{$\begin{array}{l}\text { DECISIONES EN } \\
\text { RECURSOS DE } \\
\text { COMPETENCIA }\end{array}$} & \multirow[t]{2}{*}{$\begin{array}{l}\text { DECISIONES } \\
\text { EN CONFLICTOS }\end{array}$} & \multirow[t]{2}{*}{ INCONSTITUCIONALIDAD } \\
\hline & EXITO & FRACASO & & \\
\hline Cataluña & 47.10 & 52.88 & 104 & 44 \\
\hline Aragón & 40.77 & 59.22 & 29 & 5 \\
\hline Islas Baleares & 39.58 & 60.41 & 18 & 9 \\
\hline Canarias & 38.70 & 61.29 & 23 & 7 \\
\hline Galicia & 36.51 & 63.48 & 31 & 12 \\
\hline País Vasco & 34.55 & 65.43 & 82 & 37 \\
\hline Andalucía & 32.72 & 67.27 & 33 & 6 \\
\hline \multicolumn{5}{|c|}{$\begin{array}{c}\text { Índice Conflictividad y Éxito Gubernamental: } \mathbf{5 8 . 9 0} \\
\text { (ver cuadros estadísticos de la investigación referida en nota al pie N.o } 15 \text { ) }\end{array}$} \\
\hline \multicolumn{5}{|c|}{$\begin{array}{l}\text { Fuente: elaboración propia de acuerdo a base de datos construida, extrayendo } \\
\text { información de autos y sentencias de la web-page del TC. }\end{array}$} \\
\hline
\end{tabular}

La mejor performance de Cataluña en su confrontación jurisdiccional contra el Gobierno la obtiene cuando son atacadas sus normas autonómicas. En esa variable sólo el $42 \%$ de los casos impulsados por el gobierno tiene éxito y obtiene una declaración de inconstitucionalidad de normas catalanas. Es el porcentual más bajo en relación a todas las CC.AA., considerando el mismo escenario donde el gobierno impugna normas autonómicas. Aún así, lograr en un $42 \%$ de los casos la inconstitucionalidad pretendida es una performance exitosa para el gobierno, aunque sea la menos exitosa considerando a todas las CC.AA. 
Galicia es la CC.AA. que obtiene mejores porcentuales cuando impugna normas nacionales con el $41 \%$ de declaración de inconstitucionalidades (cuadro $N^{\circ} 5$ ).

Por ello, no obstante la performance relativa de Cataluña, y también de Galicia, como ya se ha dicho, el gobierno presenta un ICEA muy superior a todas las CC.AA., incluso notoriamente más exitoso que Cataluña, lo que demuestra, a su vez, que la jurisdicción constitucional le resulta muy favorable como ámbito de resolución del conflicto político-competencial-jurídicoconstitucional, que lo confronta con las CC.AA. (cuadros $N^{\circ} 4$ y5).

\section{Cuadro N..$^{\circ} 5$}

\begin{tabular}{|c|c|c|c|}
\hline \multicolumn{4}{|c|}{ Comparativo de performances entre gobierno y CC.AA. ${ }^{(1)}$} \\
\hline \multirow{2}{*}{1} & \multirow{2}{*}{ Cataluña } & Decisiones favorables al gobierno & $28 \mathrm{~s} /$ total de $66: 42 \%$ \\
\hline & & Decisiones favorables a Cataluña & $27 \mathrm{~s} /$ total de $92: 29 \%$ \\
\hline \multirow{2}{*}{2} & \multirow{2}{*}{ País Vasco } & Decisiones favorables al gobierno & 27 s/ total de $48: 56 \%$ \\
\hline & & Decisiones favorables al País Vasco & $19 \mathrm{~s} /$ total de $64: 30 \%$ \\
\hline \multirow{2}{*}{3} & \multirow{2}{*}{ Galicia } & Decisiones favorables al gobierno & $12 \mathrm{~s} /$ total de $23: 52 \%$ \\
\hline & & Decisiones favorables a Galicia & $12 \mathrm{~s} /$ total de $29: 41 \%$ \\
\hline \multirow{2}{*}{4} & \multirow{2}{*}{ Andalucía } & Decisiones favorables al gobierno & $5 \mathrm{~s} /$ total de $10: 50 \%$ \\
\hline & & Decisiones favorables a Andalucía & $8 \mathrm{~s} /$ total de $27: 30 \%$ \\
\hline \multicolumn{4}{|c|}{$\begin{array}{l}\text { 1) Según datos extraídos de los cuadros estadísticos de la investigación referida en nota } \\
\text { al pie N. }{ }^{\circ} 15\end{array}$} \\
\hline \multicolumn{4}{|c|}{$\begin{array}{l}\text { Fuente: Elaboración propia de acuerdo a base de datos construida, extrayendo } \\
\text { información de autos y sentencias de la web-page del TC. }\end{array}$} \\
\hline
\end{tabular}




\section{CONCLUSIONES PARA EL CASO ESPAÑOL}

Lo expuesto en este apartado en relación al caso español permite esgrimir las siguientes conclusiones debidamente verificadas:

1) Sin perjuicio del desarrollo autonómico sostenido y de la conflictividad competencial creciente, la legislación nacional continúa siendo el sustento mayoritario y dominante del derecho común en el sistema jurídico español.

2) Ello es también demostrativo de que las competencias administrativas, jurisdiccionales y políticas continúan con preponderancia en manos del Estado central.

3) La puja competencial entre el Estado central y las CC.AA. es el conflicto más relevante que debe resolver el TC, por lo que su performance se ve envuelta en una conflictividad de alto voltaje político. Del total de inconstitucionalidades (tanto en jurisdicción nacional como autonómica) declaradas por el TC, el $68 \%$ fue en recursos de inconstitucionalidad y conflictos de competencia, esto es, en conflictos competenciales donde confrontan los órganos políticos legitimados por el Art. 162.1.a CE. Sólo el $32 \%$ de declaraciones de inconstitucionalidades se produce ante cuestiones de inconstitucionalidad. (cuadro $N .^{\circ} 2$ ).

4) Refuerza sólidamente lo expuesto que el $72 \%$ de las sentencias para normas autonómicas se producen en recursos de inconstitucionalidad y conflictos de competencia, porcentual que aumenta al $82 \%$ en sentencias que declaran inconstitucionalidades, ello significa que la conflictividad autonómica es competencial y entre los órganos políticos legitimados por el Art. 162.1.a CE. 
5) Tanto en recursos de inconstitucionalidad como en conflictos de competencia, el gobierno fue el más activo órgano impulsor (Art. 162.1.a CE) de los procesos, lo fue en un $57 \%$ y un $46 \%$ respectivamente. En los conflictos de competencia siguen como impulsores Cataluña con el $28 \%$ y el País Vasco con el $22 \%$. Esto indica que la vía procesal de los conflictos positivos de competencia en los cuales se piden inconstitucionalidades (la investigación sólo ha tomado los conflictos en esos casos) es un instituto procesal monopolizado por esos tres actores políticos, el Gobierno nacional y las instituciones políticas de Cataluña y el País Vasco.

6) Como corolario de lo que se viene exponiendo, las declaraciones de inconstitucionalidades de normas autonómicas que son, proporcionalmente, casi el doble que para las nacionales, demuestra que esa puja competencial y política entre las CC.AA. y el Estado nacional se resuelve, mayoritariamente, a favor del Estado nacional.

Esta conclusión es también sustentable de acuerdo a lo observado en los cuadros estadísticos de la investigación referida, a través del índice de conflictividad y éxito autonómico (ICEA), que demuestra que el gobierno posee un índice de éxitos ante el TC muy superior a las CC.AA. 


\section{BIBLIOGRAFÍA}

AJA, Eliseo y PÉREZ TREMPS, Pablo. “Tribunal Constitucional y organización del estado autonómico" - En ESPÍN TEMPLADO, Eduardo y DÍAZ REVORIO , Javier (coords.), La justicia constitucional en el estado democrático, Valencia: Tirant Lo Blanch, 2000.

AJA, Eliseo. Estado Autonómico y Reforma Federal, Madrid: Alianza Editorial, 2014.

ANDERSON, George. Federalism: An introduction, Canada: Oxford University Press, 2008.

ARAGÓn REYES, Manuel. "25 años de justicia constitucional en España", Revista Iberoamericana de Derecho Procesal Constitucional, Sd, Porrúa, 2004.

. Constitución y Democracia, Madrid: Tecnos, 1989.

BARRERA, Leticia. La Corte Suprema en escena. Una etnografía del mundo judicial, Buenos Aires: Siglo XXI, 2012.

BERCHOLC, Jorge. Temas de Teoría del Estado, Buenos Aires: Editorial La Ley, 2014. 
- La performance del Tribunal Constitucional español a través del ejercicio del Control de Constitucionalidad (1980-2011). Un estudio sobre las relaciones entre el Tribunal Constitucional y el sistema político-institucional de España.

En impresión, en Argentina por editorial EDIAR, y en España por la editorial Tirant Lo Blanch.

BURNHAM, James. Los Maquivelistas, sd, Olcese Editores, 1986.

DÍAZ REVORIO, Javier. La Constitución como orden abierto, Sd, Mc Graw-Hill, 1997.

- Valores superiores e interpretación constitucional, Madrid: CEPC, 1997.

DE eSTEBAn, J., Curso de Derecho constitucional español III, Madrid: sd, p. 28, 1994.

LÓPEZ GUERRA, Luis. Las relaciones entre el ordenamiento estatal y los ordenamientos autonómicos en Derecho constitucional, Valencia: Tirant lo Blanch, 2003.

MOLINELli, Guillermo, PALANZA, Valeria y SIN, Gisela. Congreso, Presidenciay Justicia en Argentina. Materiales para su estudio, Buenos Aires: Temas, 1999.

NOHLEn, Dieter. Diccionario de Ciencia Política, México: Editorial Porrúa, 2006. 
ORTEGA ALVAREZ, Luis. “¿Estado federal, integral o autonómico?”, en TUDELA ARANDA, Jose y KNÜPLING, Félix, (Edits.), España y modelos de federalismo, Madrid: Fundación Manuel Giménez Abad y Centro de Estudios Políticos y Constitucionales, 2010.

PÉREZ ROYO, Javier. Curso de Derecho Constitucional, Madrid: Marcial Pons, 1994.

PÉREZ TREMPS, Pablo. Derecho Constitucional, El Tribunal Constitucional, Volumen II, AA.VV., Valencia: Tirant lo Blanch, 2003.

WATTS, Ronald. Sistemas federales comparados, Madrid: Marcial Pons, 2006.

. España: ¿Una federación multinacional encubierta? en TUDELA ARANDA, José y KNÜPLING, Félix (Edits.), España y modelos de federalismo, Madrid: Fundación Manuel Giménez Abad y Centro de Estudios Políticos y Constitucionales, 2010. 